\title{
Application of Color and Musical Language in Chinese Contemporary Animation Film
}

\author{
Peng Jing \\ Academy of Arts and Films \\ Chengdu University \\ Chengdu, China 610106
}

\begin{abstract}
With quickening space of domestic modernization construction, people's material and culture life standard gets promoted continuously and art industry also obtains extremely rapid development. As an important branch of art, contemporary animation film develops with an objective speed under current social background. In terms of the essence of animation film, as two important elements, application of color and musical language must be excellent. Their application is mainly directly related to film theme, creation background, creator's personal emotion and so on. Based on the above elements influencing color and musical language, the author starts with three aspects: nationality and strengthening of folk characteristics, realism and reproduction, and symbolism and personalization, and systematically analyzes application of color language and musical language in Chinese contemporary animation film, hoping to provide some theoretical reference for colleagues in this industry to carry out relevant work.
\end{abstract}

Keywords-Chinese contemporary animation; animation film; color fable; musical language

\section{INTRODUCTION}

As an important branch of contemporary film art, animation film relies on its rich picture and appropriate music to mobilize audiences' visual sense, auditory sense etc., meeting consumers' aesthetic need and spiritual need at the same time. Application of color language and musical language in Chinese contemporary animation film is mainly directly related to film theme, creation background and creator's personal emotion and so on. Reasonable application of them can not only present the visual scene desired by the creator and audience in a concrete way, but also effectively promote communication between the creator and consumers in the spiritual level. Lots of benefits have been obtained through a systematic analysis on characteristics of and changes in application of color language and musical language in Chinese contemporary animation film and the report on it is as follows.

\section{APPLICATION FEATURES OF AND CHANGES IN COLOR LANGUAGE IN CHINESE CONTEMPORARY ANIMATION FILM}

Since the early stage of last century when color film appears, film art gradually develops rapidly. Currently, a

*This paper is a staged achievement of Sichuan Province's animation center subject ----Research on Chinese Animation Film Music in Recent Ten Years. Project No.: DM201620 gradual transition from the original two-dimensional way of presentation to popularization of $3 \mathrm{D}$ film is completed. Undoubtedly, in the development process of film, color language plays an important role, being an excellent catalyst for development of film art. It can be said that as an important means of expression for film creation, color language can effectively convey the emotion, idea and thought contained in the film, thus reflecting value orientation and aesthetic needs in the work. Based on it, since animation film has the characteristic of non-live shot, the expressive force of color in the corresponding animation work is even more prominent. Therefore, application of color language has to achieve the goal of expressing roles' emotion and building scene atmosphere. Originally speaking, color language is an important component with the highest appreciation value of animation film, and it plays an excellent role in promoting animation film's aesthetic interest, which can not be paralleled by other designed languages. In the author's point of view, application of color language in Chinese contemporary animation film and its characteristic changes are mainly manifested in the following several aspects:

\section{A. Intensify Nationality and Folk Characteristics}

Generally speaking, under different humanistic backgrounds and conditions of national features, there are great differences in color language's means of expression. To some extent, application of color language can reflect nationality and folk characteristics. For example, in modern animation film works, like Nezha Conquers the Dragon King, Havoc in Heaven, Lotus Lantern and Monkey King: Hero is Back, application of color language has strong nationality and folk characteristics. The shade is suitable with excellent picture effect, satisfying aes thetic needs of audiences at all levels and creating extremely high realistic value and social effect.

We can start with application of color language which is based on "strong" color in contemporary animat ion works. The "strong" color here mainly refers to bright color, which can not only meet aesthetic needs of people of various nations for color combination, but also further display vividness of the film. Take Havoc in Heaven, Lotus Lantern and Monkey King: Hero is Back as instances, bright red, brilliant blue, brilliant yellow and other bright and lively colors are used in them, creating a strong visual impact for audience. In terms of the meaning of each color in China's historical development, red is always loved in China, therefore it is also called Chinese red, 
representing prosperity and celebration and giving people the feeling of excitement and vigor. In addition, to some extent, red can also represent impulsion and angry feelings. In terms of application of red color in Monkey King: Hero is Back, since the role is defined as ruthless, tyrannical and petulance, red color is frequently used. When the monkey king gets furious and tries to get rid of the shackles, his red cloak extends to the whole scene, which can mobilize the audience's emotion and contribute to achieving spiritual resonance. In addition, brilliant yellow has an extremely distinguished symbolic meaning in China since ancient times and it is the exclusive color of ancient emperor. It is exactly because Zhao Kuangyin is draped with the imperial yellow robe that he has to rebel, becoming the founding emperor of Song Dynasty. Therefore, the distinguished implication contained in yellow can't be ignored. In Lotus Lantern, various places in heavenly palace take bright yellow as the keynote, which demonstrates the distinguished heaven palace in color and the courage and persistence needed for Chen Xiang to save his mother from one side. Thus, it is easy to draw the conclusion that application of color language in Chinese contemporary animation film is inseparable from the meaning of color combination in China since ancient times, further reflecting national features in color application.

Seeing from facial color combination of Sun Wukong in Havoc in Heaven, the face design combines traditional Beijing Opera art's facial makeup image and folk paper cut arts. To some extent, the color combination integrates with Chinese traditional folk art culture's es sence. Application of yellow and red not only displays the rebellion revealed from the role image's bone, but also displays his optimis mand confidence. It can not be denied that after integration of folk artistic color combination into this role, Sun Wukong's rebellious image does not arouse disgusted feelings. Instead, it makes the audience feel quite close, reflecting the specific effect of applying folk color combination model in color of contemporary animation film. In addition, in Nezha Conquers the Dragon King and Golden Conch, "strong" color language is widely used with distinctive features of Chinese traditional folk color combination, further displaying features of domestic nations and folk color.

As to application of "light" color language in contemporary animation works, water-and-ink animation films, like Little Tadpoles Search for Their Mother and Feelings of Mountains and Waters, reflect the feature of "regarding one's ink as if it were gold". As the saying goes, strong color has its own flavor and light color has its own sentiment. This type of animation film work fully reflects the aesthetic orientation of "light" color. Little Tadpoles Search for Their Mother is based on creative ideas of Qi Baishi and other Chinese painting masters. The whole layout takes black, white and gray as its main color motif and some elegant colors are added in some fragments to make them fresh and bright, creating a relatively soothing atmosphere and reflecting the artistic conception pursued by Chinese realm of art for a long time.

\section{B. Realism and Representation}

In the present society, animation film art continuously develops and Chinese contemporary animation film's sampling is no longer limited to China's ancient mythology, legend and folk story. Relying on current network, animation TV series, children's online games and so on have become the important sampling of contemporary animation film creation. For instance, in recent years, animation films, like Pleasant Goat and Big Big Wolf, Legend of The Moles -- The Frozen Horror and so on, hit hundreds of million at the box office. This type of artistic works usually gives people strong feelings and a sense of excitement. As one of the important languages of artis tic creation and expression, color definitely has the features of reality and imagination and shows the differences between representation and expression. As to this type of film, the description is not about figures and scenes of life in reality. Its story line and theme are usually quite simple with the problem of blind pursuit of children fun. Quite a number of moral elements and the so-called life philosophy of adults in nowadays are implanted in the film. Therefore, it demonstrates strong realis $\mathrm{m}$ with prominent artis tic features of representation.

In terms of environment color, the above animation works usually adopt the way of cold and warm tones contrast to bring strong visual impact and psychological aesthetic impact to audience. Colors in this type of film are usually strong and chaotic. Application of color language in Legend of The Moles -- The Frozen Horror is extremely exaggerated. Seeing from animation film itself, application of color language should achieve the effect of harmony and unity. Therefore, in the process of applying color in animation film, the standard should be obeyed properly in order to meet visual, aes thetic and spiritual needs of audience.

\section{Symbolism and Personalization}

It can be said that animation film is the representative of non-real shot film. It is integrated with the creator's strong subjective sense and emotion, thus it has strong personal color. This type of film demonstrates distinctive symbolic features in color language and can effectively realize manifestation of history humanities, manners and customs. In terms of symbolism and personalization of color language movement, we can take Kung Fu Panda for an example. This film is integrated with many Chinese elements, like food, color, Kung $\mathrm{Fu}$ and so on. In terms of color, the introduction of panda image with black and white as color motif not only displays a panda's actual features in a true-life way, but also integrates Chinese Taoism and ideas in the Book of Changes metaphorically, having strong township significance. In addition, the film's background colors are relatively unified. For example, red is often used in Chinese restaurant, which reflects China's cultural capital to some extent. Architectural images are integrated with Chinese national features and cultural value orientation in the form of ink and wash painting. It is different from emphasizing on display of nationality and folk nature. Solidification of color combination endows the shaped image with typical symbolic meaning and endows the animation film with distinctive personalized features at the same time.

\section{APPLICATION FEATURES OF AND CHANGES IN MUSICAL LANGUAGE IN CHINESE CONTEMPORARY ANIMATION FILM}

Although application of musical language in contemporary animation film can not directly construct picture scenes of the 
film in a concrete way, it can not be denied that it has quite great influence on the picture's expressive force and artistic sense. In the development process of domestic animation film, as an important language for artistic expression, music itself is endowed with distinctive characteristics of the times. In terms of musical style, from last century to current development, it has obtained rich contemporaneity and diversification features. It can be said that Chinese contemporary animation film's success can't be separated from rational use of musical language. Take Havoc in Heaven as an example, it displays distinctive national features in color combination and pushes national features to another climax in application of musical language. For example, in the process of Sun Wukong's fighting, gong and drum and other folk percussion instruments are frequently used. Lively, vivid and enthusiastic musical features demonstrate distinctive national features. Seen from background music of fight scenes, it has typical Beijing dialect features. Observing carefully, it is not difficult to find that the animation work is integrated with Beijing dialect and rhy me of Beijing Opera and corresponding classical. It is just like Chinese traditional jubilant music, bringing you magnificent and strong feelings.

With extraordinary development of domestic animation film, its musical material gets richer and richer. During the time when Lotus Lantern is created, certain popular elements have been integrated into musical language of animation film. Besides, distinct elegant temperament is reflected in application of musical sounds, effectively realizing integration of music and the scene. It can mobilize audience's visual sense and it is extremely favorable for improving influence of animation film. It can be said that reasonable application of musical language in animation works and application of color language can supplement each other, which can contribute to communication between the creator and audience in the spiritual level. In addition, apart from application of traditional musical instruments in background music of animation film, western instruments are also used, like violin, piano and so on, further enriching musical forms of animation film.

Seen from application of musical language in The Radiant Goat and the Grey Wolf----As Dynamic as a Tiger released in recent years, its music theme creation and background music are integrated with currently popular electronic music. It is also assisted by special sound processing on the internet to realize organic combination of orchestral music and drumbeat. Thus, the bright and lively picture is integrated with musical sounds, mobilizing audience's emotional factors and further displaying the goat's lively, positive and objective traits of character.

Seeing from the history development of Chinese contemporary animation film, primarily there is no exclusive theme song or interlude and there is only some simple background music. Take Princess Iron Fan, the first animation film made by China, as an example, musical language used in it is just to further demonstrate figures' inner emotion, action scene and screen layout. The later released Havoc in Heaven contains similar application of musical language. With continuous development of animation film art, its application forms and types of musical language gradually become abundant, and expressive force of emotion and artistic conception is also promoted. Take Lotus Lantern as an example, through application of theme song and interlude, it pulls open a brand new prelude of domestic animation film development, having milestone significance. Since then, background music of animation film is no longer simple pure music. It effectively achieves high integration with color language and fully shows figures' inner emotion, playing a significant role in development of Chinese contemporary animation film

\section{CONCLUSION}

In conclusion, in the development of Chinese animation film, application mode of color language and musical language is constantly renovated and creation effect is quite evident. Therefore, in the successive animation film creation process, relevant personnel must use color language and musical language well and constantly improve uniqueness of color combination and musical art in order to meet audience's diversified aesthetic and emotional needs and lay a solid foundation for development of domestic animation film.

\section{REFERENCES}

[1] Ning Xiang. Nationalization and Internationalization of Chinese Contemporary Animation Film[J]. Film Literature, 2016,(19):100-102.

[2] Feng Rui, Dai Yuanyuan. Creation and Development of Aesthetic Characteristics of Contemporary Chinese Animation Film-Take Monkey King: Hero Is Back as an Example[J]. Hundred Schools in Arts, 2016,(04):247-249.

[3] Lai Ningyi. Aesthetic Value of Music in Joe Hisaishi's Animation Film and Its Enlightenment on Music in Chinese Animation Film[J]. Culture Journal, 2015,(11):74-77.

[4] Liu Rui. Analysis on National Musical Element's Influence on Chinese Animation Film's Cultural Ecology[J]. Film Literature, 2014,(09):57-58. 